\title{
Meta-Analysis of Suicide-Related Behavior or Ideation in Child, Adolescent, and Adult Patients Treated with Atomoxetine
}

\author{
Mark E. Bangs, MD, Linda A. Wietecha, BSN, MS, Shufang Wang, PhD, \\ Andrew S. Buchanan, BS Pharm, and Douglas K. Kelsey, MD
}

\begin{abstract}
Objective: This meta-analysis examined suicide-related events in the acute phases of double-blind, placebo-controlled atomoxetine trials in pediatric and adult patients with attention-deficit/hyperactivity disorder (ADHD).

Methods: A total of 3883 pediatric and 3365 adult patients were included. Potential events were identified from the adverse events database using a text-string search. Mantel-Haenszel risk ratios (MHRR) were calculated for potential suicide-related events categorized according to United States Food and Drug Administration defined codes.

Results: In this data set, no completed suicides were reported in the pediatric or adult populations. One pediatric (attempted suicide) (and no adult patient events) was categorized as suicidal behavior in the atomoxetine group. The frequency of combined suicidal behavior or ideation with atomoxetine treatment was $0.37 \%$ in pediatric patients (vs. $0.07 \%$ with placebo) and $0.11 \%$ in adults (vs. $0.12 \%$ with placebo) and the risk compared with placebo was not statistically significant ( $\mathrm{MHRR}=1.57 ; p=0.42$ and MHRR $=0.96 ; p=0.96$, respectively). In pediatric patients, suicidal ideation only was reported more frequently compared with placebo $(\mathrm{MHRR}=1.63 ; p=0.41)$.

Conclusions: Overall in this data set, no completed suicides and 1 pediatric patient suicidal behavior event were reported in atomoxetine-treated pediatric and adult patients. Suicidal ideation was uncommon among atomoxetine-treated pediatric and adult patients, although it was reported more frequently in atomoxetine-treated pediatric patients compared with placebo; the reporting rate difference was not statistically significant. The MHRR of suicidal ideation was consistent with a previous metaanalysis of similar design. There was no evidence of increased risk for suicidal behavior in atomoxetine-treated pediatric or adult patients.

Clinical trial registration information: http://www.clinicaltrials.gov. The data reported are from an analysis of 23 pediatric and 9 adult clinical trials completed between 1998 and 2011. Ten pediatric (Studies HFBD, HFBK, LYAC, LYAS, LYAT, LYAW, LYAX, LYBG, LYBI, and LYBP) and two adult trials (Studies LYAA and LYAO) were conducted before the requirement to post trials at initiation (ongoing as of July 1,2005) and, therefore, do not have a registration number. The registration numbers for the 13 pediatric trials meeting this requirement are: NCT00191698 (LYBX), NCT00486122 (LYCC), NCT00386581 (LYCZ), NCT00485459 (S010), NCT00191542 (LY15), NCT00191295 (LYBC), NCT00191906 (LYCK), NCT00192023 (LYCY), NCT00191945 (LYDM), NCT00546910 (LYDV), NCT00406354(LYDW), NCT00380692 (S017), and NCT00607919 (LYEB). For the seven adult trials, the registration numbers are: NCT00190931 (LYBV), NCT00190957 (LYBY), NCT00190736 (LYCU), NCT00190775 (LYCW), NCT00190879 (LYDQ), NCT00510276 (LYDZ), and NCT00962104 (LYEE).
\end{abstract}

\section{Introduction}

A TTENTION-DEFICIT/HYPERACTIVITY DISORDER (ADHD), is a common psychiatric disorder in children and adolescents that can persist into adulthood (Biederman and Faraone 2002; Biederman 2005; Barkley et al. 2008; Wittchen et al. 2011). Estimates of the prevalence of ADHD range from $5 \%$ to $10 \%$ in pediatric patients and from $2.5 \%$ to $5 \%$ in adult patients (Biederman 2005;
Kessler et al. 2006; Barkley et al. 2008; Simon et al. 2009; Willcutt 2012; Centers for Disease Control and Prevention 2013; Perou et al. 2013). Complicating the clinical presentation is the fact that children, adolescents, and adults with ADHD are often at higher risk than the general population for other psychiatric disorders including mood disorders, antisocial or aggressive behaviors, and substance abuse (Spencer et al. 1999; Willcutt et al. 1999; Biederman 2005; Kessler et al. 2006). The frequency of suicidal behavior or

Eli Lilly and Company, Indianapolis, Indiana. 
ideation is often greater in children, adolescents, and adults with psychiatric disorders including ADHD than in those without mental illness (Brent et al. 1988; Houston et al. 2001; O'Donnell et al. 2005; Impey and Heun 2012). A review of publications evaluating the relationship between ADHD and suicide-related events in pediatric and adult patients showed that the rate of ADHD diagnosis ranged from $4 \%$ to $25.9 \%$ in the population of patients with completed suicides, which is higher than general pediatric and adult population estimates of ADHD prevalence (Impey and Heun 2012). Compounding the risk, comorbidities occurring with ADHD may be associated with an increased risk of suicidal behavior or ideation (Brent et al. 1988; Shafii et al. 1988; James et al. 2004; McCarthy et al. 2009; Impey and Heun 2012).

Atomoxetine, a highly selective inhibitor of norepinephrine transporters with low affinity for serotonin and dopamine transporters, is effective in the treatment of ADHD in children, adolescents, and adults (Bymaster et al. 2002; Swanson et al. 2006). In 2008 , Lilly published a meta-analysis that examined suicide-related events in placebo-controlled atomoxetine pediatric $(n=12)$ and adult $(n=9)$ trials in which no completed suicides for either population was reported (Bangs et al. 2005, 2008b). In the pediatric population, suicidal ideation, although uncommon, was reported more frequently by atomoxetine-treated pediatric patients than by those treated with placebo $(0.37 \%$ vs. $0 \%$, respectively). The reporting rate difference between treatment groups was not statistically significantly different (Bangs et al. 2008b). Analysis of adult clinical trials included patients with ADHD and major depression (MDD). The frequency of suicidal behavior or ideation for patients with either ADHD or MDD was not significantly different between atomoxetine $(15 / 1718 ; 0.87 \%)$ and placebo $(10 / 1072 ; 0.93 \%)$ groups. In adult patients with ADHD treated with atomoxetine, no suicidal behavior or ideation were reported (Bangs et al. 2005). The present meta-analysis is a continuation of surveillance to assess the risk of suicide-related events in a larger pool of pediatric and adult patients with ADHD from the acute phase of double-blind, placebocontrolled atomoxetine clinical trial databases.

Since the previous analysis, the United States Food and Drug Administration (FDA) put forth recommendations that all clinical trials in psychiatric populations utilize the Columbia Suicide Severity Scale (C-SSRS) as an additional tool to assess the severity of suicidal ideation (Posner et al. 2007, 2011; United States Department of Health and Human Services Food and Drug Administration Center for Drug Evaluation and Research 2013). In the present meta-analysis, outcomes from three double-blind, placebo-controlled atomoxetine clinical trials that utilized the C-SSRS are also described.

\section{Method}

The current analysis evaluated the acute phase of double-blind, placebo-controlled studies of atomoxetine conducted by Eli Lilly and Company in pediatric and adult patients with ADHD. Details of the studies have either been previously published or the information has been posted at www.clinicaltrials.gov or www.lillytrials.com (Michelson et al. 2001, 2002; Spencer et al. 2002; Michelson et al. 2003; Kelsey et al. 2004; Allen et al. 2005; Weiss et al. 2005; Bangs et al. 2007; Gau et al. 2007; Geller et al. 2007; Adler et al. 2008; Bangs et al. 2008a; Newcorn et al. 2008; Wilens et al. 2008; Adler et al. 2009a,b; Block et al. 2009; de Jong et al. 2009; Montoya et al. 2009; Dell'agnello et al. 2009; Svanborg et al. 2009; Takahashi et al. 2009; Martenyi et al. 2010; Dittmann et al. 2011; Young et al. 2011; Harfterkamp et al. 2012; Hirata et al. 2012; Wehmeier et al. 2012; Durell et al. 2013; Wietecha et al. 2013). Study designs excluded from analysis included open-label trials, randomized withdrawal study design, and studies with extended lead-in phases. Trials included in the data set were completed between 1998 and 2011 in the United States, Japan, Australia/Canada/Europe (ACE), and the following other countries: Argentina, Belgium, China, Israel, Korea, Mexico, South Africa, and Taiwan. Data from 23 pediatric trials included a total of 3883 pediatric patients (atomoxetine, $n=2445$; placebo, $n=1438$ ) and ranged from 35 to 108 days (5-15 weeks) in duration. Data from nine adult trials included a total of 3365 adult patients (atomoxetine, $n=1764$; placebo, $n=1601$ ) and ranged from 62 to 141 days (9-20 weeks) in duration. Both pediatric and adult trials included once or twice daily dosing regimens. The mean daily dose range of atomoxetine was 0.89 $1.36 \mathrm{mg} / \mathrm{kg}$ in the pediatric trials (weight-based dosing) and 72.47 $90.34 \mathrm{mg}$ in the adult trials.

Pediatric and adult patients met American Psychiatric Association: Diagnostic and Statistical Manual of Mental Disorders, 4th ed., Text Revision (DSM-IV-TR) criteria for ADHD (American Psychiatric Association 2000). The pediatric population also included patients with comorbid conditions of tics, depression, anxiety, oppositional defiant disorder (ODD), reading disorder, autism spectrum disorder, and dyslexia (Allen et al. 2005; Bangs et al. 2007; Geller et al. 2007; Bangs et al. 2008a; de Jong et al. 2009; Dell'agnello et al. 2009; Dittmann et al. 2011; Harfterkamp et al. 2012; Wietecha et al. 2013). The adult population included patients with comorbid social anxiety and alcohol use disorders (Wilens et al. 2008; Adler et al. 2009a). In general, patients in both populations were required to be of normal intelligence. Generally, exclusion criteria included history of psychosis, bipolar disorder, or seizure disorder; serious suicidal or homicidal risk; or organic brain disease. The pediatric studies also excluded patients with a history of excessive alcohol or drug abuse within the past 3 months. Each clinical trial included in the analysis had institutional review board (IRB) approval (study level and site level) and was conducted in accordance with the Declaration of Helsinki. All adult patients and a parent or guardian for each minor patient provided written informed consent to participate (Michelson et al. 2001, 2002; Spencer et al. 2002; Michelson et al. 2003; Kelsey et al. 2004; Allen et al. 2005; Weiss et al. 2005; Bangs et al. 2007; Gau et al. 2007; Geller et al. 2007; Adler et al. 2008; Bangs et al. 2008a; Newcorn et al. 2008; Wilens et al. 2008; Adler et al. 2009a,b; Block et al. 2009; de Jong et al. 2009; Dell'agnello et al. 2009; Montoya et al. 2009; Svanborg et al. 2009; Takahashi et al. 2009; Martenyi et al. 2010; Dittmann et al. 2011; Young et al. 2011; Harfterkamp et al. 2012; Hirata et al. 2012; Wehmeier et al. 2012; Durell et al. 2013; Wietecha et al. 2013).

Potential suicide or self-harm-related events were identified by a computerized text-string search of all of the electronically available data in the Eli Lilly and Company clinical trials database, including all adverse events (reported and coded) and narratives for the 23 pediatric and 9 adult double-blind, placebo-controlled trials of atomoxetine. The text-strings used in the search for this analysis included search terms used in a previous analysis requested by the FDA (Bangs et al. 2008b) supplemented by additional terms (shown in italics) for a more comprehensive review: aggression, asphyxia, attempt, burn, cut, damag, death, die, drown, dsh, dying, emotion, exhaust, firearm, gas, gun, injur, intent, hang, harm, hostil, hung, ideation, immolat, inflict, injur, jump, kill, lability, lac, live, life, mani, monoxide, mutilat, o.d., o/d, od, overdos, plastic, poison, railway, rifle, s.h., shoot, shot, s.i., si, slash, suic, suffocat, toxic. A review of the identified events retrieved with these terms was conducted, and events unrelated to suicidality or self-harm were 
excluded (e.g., diet, heartburn, hungry, hangover). Events that occurred before randomization and did not worsen after randomization or occurred $>1$ day after the last dose were excluded. Blinded patient summaries of unexcluded cases provided additional clinical information (including investigator comments, demographic information, medical history, and psychiatric comorbidities) relevant to the cases and were the basis for categorization of potential suicide-related events using FDA-defined codes (Posner et al. 2007, 2011; United States Department of Health and Human Services Food and Drug Administration Center for Drug Evaluation and Research 2013). Review of blinded patient summaries were conducted by two trained healthcare professionals from Eli Lilly and Company (at least one was a physician) who were also trained to use the FDA codes. Working independently of each other, each employee categorized the summaries according to the following list of FDA-defined codes:

Code 1: completed suicide

Code 2: suicide attempt

Code 3: preparatory acts toward imminent suicidal behavior

Code 4: suicidal ideation

Code 5: self-injurious behavior, intent unknown

Code 6: not enough information, fatal

Code 7: self-injurious behavior, no suicidal intent

Code 8: other: accident, psychiatric, medical

Code 9: not enough information, nonfatal

A third trained healthcare professional from Eli Lilly and Company adjudicated cases in which there was disagreement.

To better describe the severity of suicidal behavior or ideation, a subanalysis of studies that used the C-SSRS measure at the time of analysis was conducted. The C-SSRS was utilized in one pediatric study (LYEB) conducted in the United States in patients with ADHD and comorbid dyslexia, and two adult trials (LYDZ and LYEE) conducted in the United States specifically in young adults or Asian adults with ADHD (Hirata et al. 2012; Durell et al. 2013; Wietecha et al. 2013). The C-SSRS was designed to distinguish the domains of suicidal behavior and suicidal ideation by measuring the following four constructs: 1) Severity of ideation, 2) intensity of ideation, 3) behavior, and 4) lethality. Two of the four constructs were mapped to FDA-defined codes: Suicidal ideation (composed of five items, each rated on a five point ordinal scale that included frequency, duration, controllability, deterrents, and reason for ideation) and behavior (rated on a nominal scale that included actual, aborted, and interrupted attempts; preparatory behavior; and nonsuicidal self-injurious behavior) (Posner et al. 2007, 2011). Suicidal behavior by FDA-defined codes was mapped to suicidal behavior items 6-10 of the C-SSRS (includes preparatory acts or behavior; aborted, interrupted, and nonfatal attempts; and completed suicide). FDA codes for suicidal ideation were mapped to suicidal ideation items 1-5 of the C-SSRS (includes thoughts of wishing to be dead, nonspecific active suicidal thoughts, active ideation with any method without intent to act, active ideation with some intent to act without a specific plan, and active ideation with a specific plan and intent) (Posner et al. 2011).

\section{Statistical analysis}

Meta-analysis of the proportion of patients with a suicide-related event was conducted. The following four suicide-related outcomes were analyzed: Suicidal behavior (FDA Codes 1-3), suicidal ideation (FDA Code 4), combined suicidal behavior or ideation (FDA Codes 1-4), and possible suicidal behavior or ideation (FDA Codes
1-6 and 9). The incidence for each treatment arm was based on pooled data. The percentages of each suicide-related outcome were compared between atomoxetine and placebo groups for pediatric and adult populations using the Mantel-Haenszel Risk Ratio (MHRR), stratified by study. The MHRR and 95\% confidence intervals (CI) for the meta-analysis and each individual study were calculated using SAS Drug Development software. The MHRR is a weighted average of individual trial relative risk (atomoxetine incidence divided by placebo incidence), in which the weights allow strata with larger sizes to have larger effects on the pooled relative risk. The fixed-effects Mantel-Haenszel method, which is more likely to detect a significant difference than the random-effects method, was used for safety-related analyses (Greenland and Robins 1985; Sato 1989). Subgroup analysis using the MHRR was performed for region, age (pediatric, age $\leq 12$ vs. age $>12$ ), gender, prior stimulant use, and ADHD subtype. Demographic characteristics were compared between placebo and atomoxetine groups with $\chi^{2}$ and Fisher's exact test for categorical characteristics and one way ANOVA for continuous variables. Given the few trials with available C-SSRS data, comparison with the FDA coded textstring search was limited to descriptive statistics.

\section{Results}

The mean age of the pediatric and adult populations was 10 years and 37 years, respectively. More than half of all patients in each population were male, white, and from the United States. In each of the pediatric and adult populations, $\sim 66 \%$ of the patients presented with the combined ADHD subtype, and $\sim 30 \%$ presented with the inattentive subtype. At baseline, $50 \%$ of pediatric patients and $28 \%$ of adult patients reported prior stimulant use. In the pediatric population, the differences between treatment groups for origin and region were statistically significant, but not clinically meaningful, and not likely to have impacted the overall analysis. In the adult population, baseline characteristics between the treatment groups were not significantly different (Table 1).

The baseline characteristics of the C-SSRS pediatric subpopulation in Study LYEB were similar between treatment groups. The mean age was 12 years and all patients were from the United States. The baseline characteristics for the C-SSRS subpopulation of adults from Studies LYDZ and LYEE were similar between treatment groups, although the mean age ( 29 years) was lower than the overall meta-analysis adult population because of the age criteria for Study LYDZ. Most of the patients were from either the United States (52\%) or Japan (30\%), and 50\% of patients were of Asian descent.

\section{Suicide-related events. Text-string search: Pediatric placebo-controlled trials}

In this data set, no completed suicide events were reported for patients in either treatment arm. Suicidal behavior (possible suicide attempt) was reported for one atomoxetine-treated pediatric patient $(0.04 \%)$. This event was initially detected in the original meta-analysis (Bangs et al. 2008b). The patient was a 9-year-old white male with a past history of depression, who had been diagnosed with the combined subtype ADHD and had been randomized to atomoxetine $(1.8 \mathrm{mg} / \mathrm{kg} /$ day $)$. No suicidal behavior event was reported for the placebo group. The MHRR for suicidal behavior was $1.19(95 \%$ CI $0.05,28.96)$ and was not statistically significant $(p=0.91)$. Suicidal ideation events occurred in eight atomoxetine-treated patients $(0.33 \%)$ and in one patient in the placebo group $(0.07 \%)$. The frequency of combined suicidal behavior or ideation in pediatric patients treated with atomoxetine 
Table 1. Baseline Demographic Characteristics of Patients in Pediatric and Adult Clinical Trials

\begin{tabular}{|c|c|c|c|c|}
\hline & \multicolumn{2}{|c|}{ Pediatrics } & \multicolumn{2}{|c|}{ Adults } \\
\hline & $\operatorname{ATX}(\mathrm{n}=2445)$ & $P B O(\mathrm{n}=1438)$ & $\operatorname{ATX}(\mathrm{n}=1764)$ & $P B O(\mathrm{n}=1601)$ \\
\hline Age, years $($ mean $\pm S D)$ & $10.4 \pm 2.5$ & $10.6 \pm 2.5$ & $36.5 \pm 10.4$ & $36.0 \pm 10.5$ \\
\hline Range & $6.0-17.9$ & $6.0-17.9$ & $18.2-76.7$ & $17.6-67.5^{\mathrm{a}}$ \\
\hline \multicolumn{5}{|l|}{ Sex, $n(\%)$} \\
\hline Female & $530(21.7)$ & $324(22.5)$ & $778(44.1)$ & 707 (44.2) \\
\hline Male & $1914(78.3)$ & $1114(77.5)$ & $986(55.9)$ & $894(55.8)$ \\
\hline \multicolumn{5}{|l|}{ ADHD subtype, $n(\%)$} \\
\hline Hyperactive/impulsive & $74(3.1)$ & $36(2.7)$ & $19(1.1)$ & $23(1.4)$ \\
\hline Inattentive & $665(28.1)$ & $404(29.8)$ & $562(31.9)$ & $508(31.8)$ \\
\hline Combined & $1625(68.7)$ & $914(67.5)$ & $1181(67.0)$ & $1069(66.8)$ \\
\hline \multicolumn{5}{|l|}{ Origin*, $n(\%)$} \\
\hline White & $1745(72.6)$ & $1062(75.8)$ & $1313(74.4)$ & $1162(72.6)$ \\
\hline African descent & $177(7.4)$ & $112(8.0)$ & $82(4.6)$ & $84(5.2)$ \\
\hline Hispanic & $158(6.6)$ & $89(6.4)$ & $120(6.8)$ & $113(7.1)$ \\
\hline Asian & $272(11.3)$ & $101(7.2)$ & $225(12.8)$ & $220(13.7)$ \\
\hline Other & $53(2.2)$ & $37(2.6)$ & $24(1.4)$ & $22(1.4)$ \\
\hline \multicolumn{5}{|l|}{ Region*, $n(\%)$} \\
\hline Australia, Canada, Europe & $713(29.2)$ & $418(29.1)$ & $19(1.1)$ & $20(1.2)$ \\
\hline Japan & $183(7.5)$ & $62(4.3)$ & $124(7.0)$ & $125(7.8)$ \\
\hline United States & $1389(56.8)$ & $878(61.1)$ & $1537(87.1)$ & $1371(85.6)$ \\
\hline Other & $160(6.5)$ & $80(5.6)$ & $84(4.8)$ & $85(5.3)$ \\
\hline
\end{tabular}

Baseline demographics represent all randomly assigned patients. Only patients who received at least one dose of study drug were included in subsequent analyses.

${ }^{\mathrm{a}}$ One patient from Study LYDZ did not meet study inclusion criteria for age $\geq 18$, but was inadvertently enrolled. The patient completed the study and did not have any suicide-related events.

$* p \leq 0.001$ for pediatric population database.

ADHD, attention-deficit/hyperactivity disorder; ATX, atomoxetine; PBO, placebo.

Table 2. Suicidal Behavior and/or Ideation in Atomoxetine Pediatric AdHD Trials: Text-String Search

\begin{tabular}{|c|c|c|c|c|c|c|c|}
\hline Outcome & $\mathrm{n}$ & $\begin{array}{c}A T X \\
\mathrm{n}(\%)\end{array}$ & $\mathrm{n}$ & $\begin{array}{l}P B O \\
\mathrm{n}(\%)\end{array}$ & $\begin{array}{l}\text { Risk } \\
\text { ratio }^{\mathrm{b}}\end{array}$ & $\mathrm{p}$ value & $\begin{array}{l}\text { Risk ratio } \\
95 \% \text { CI }\end{array}$ \\
\hline \multicolumn{8}{|l|}{ All studies (all regions) } \\
\hline $\begin{array}{l}\text { Suicide completed/attempt/behavior } \\
\quad(\text { FDA Codes } 1,2,3)^{\mathrm{a}}\end{array}$ & 2445 & $1(0.04)$ & 1438 & $0(0)$ & 1.19 & 0.91 & $0.05,28.96$ \\
\hline $\begin{array}{l}\text { Suicide completed/attempt/behavior/ideation } \\
\quad \text { (FDA Codes } 1,2,3,4)\end{array}$ & 2445 & $9(0.37)$ & 1438 & $1(0.07)$ & 1.57 & 0.42 & $0.53,4.71$ \\
\hline Suicidal ideation (FDA Code 4) & 2445 & $8(0.33)$ & 1438 & $1(0.07)$ & 1.63 & 0.41 & $0.51,5.25$ \\
\hline \multicolumn{8}{|l|}{ Possible suicidal behavior or ideation } \\
\hline FDA Codes $1,2,3,4,5,6$ & 2445 & $11(0.45)$ & 1438 & $4(0.28)$ & 1.02 & 0.97 & $0.42,2.48$ \\
\hline \multirow[t]{2}{*}{ FDA Codes $1,2,3,4,5,6$, and 9} & 2445 & $14(0.57)$ & 1438 & $7(0.49)$ & 0.85 & 0.70 & $0.38,1.90$ \\
\hline & $\mathrm{n}$ & $\begin{array}{c}A T X \\
\mathrm{n}(\%)\end{array}$ & $\mathrm{n}$ & $\begin{array}{l}P B O \\
\text { n }(\%)\end{array}$ & $\begin{array}{c}\text { Overall } \\
\text { risk ratio }^{\mathrm{b}}\end{array}$ & $\begin{array}{l}\text { Overall } \\
\mathrm{p} \text { value }\end{array}$ & $\begin{array}{c}\text { Risk ratio } \\
95 \% \text { CI }\end{array}$ \\
\hline \multicolumn{8}{|l|}{ By region (all studies) } \\
\hline $\begin{array}{l}\text { Suicide completed/attempt/behavior/ideation } \\
\text { (FDA Codes } 1,2,3,4)\end{array}$ & 2445 & $9(0.37)$ & 1438 & $1(0.07)$ & 1.57 & 0.42 & $0.53,4.70$ \\
\hline Australia, Canada, Europe & 713 & $2(0.28)$ & 418 & $1(0.24)$ & 0.76 & 0.79 & $0.09,6.09$ \\
\hline Japan & 183 & $1(0.55)$ & 62 & $0(0)$ & 1.03 & 0.99 & $0.04,24.89$ \\
\hline United States & 1389 & $6(0.43)$ & 878 & $0(0)$ & 2.38 & 0.23 & $0.58,9.76$ \\
\hline Other & 160 & $0(0)$ & 80 & $0(0)$ & N/A & N/A & N/A \\
\hline
\end{tabular}

${ }^{\mathrm{a} O n e}$ event was categorized as a suicide attempt (FDA Code 2); occurred in United States; risk ratio for United States = 1.19.

${ }^{\mathrm{b}}$ Mantel-Haenszel relative risk analysis.

ADHD, attention-deficit/hyperactivity disorder; ATX, atomoxetine; CI, confidence interval; FDA, United States Food and Drug Administration; PBO, placebo. 
was $0.37 \%$ compared with $0.07 \%$ with placebo (MHRR 1.57; 95\% CI 0.53, 4.71; $p=0.42$ ) (Table 2). Possible suicidal behavior or ideation events were similar between the atomoxetine and placebo groups. Likewise, when stratified by region, differences were not significant.

The nine atomoxetine-treated pediatric patients with a suicidal behavior or ideation event were between the ages of 6.9 and 12.4 years. Nearly all patients were males (8/9) and were diagnosed with the ADHD subtypes of inattentive $(n=4)$, combined $(n=3)$, or hyperactive/impulsive $(n=2)$. Of the eight atomoxetine patients with suicidal ideation events, relevant historical or current diagnoses included: ODD $(n=5)$, obsessive-compulsive disorder $(n=1)$; dysthymia $(n=1)$, dysphoria $(n=1)$, and anxiety-specific phobias $(n=1)$, and history of suicidal behavior or ideation $(n=1)$. The placebo-treated patient with a suicidal ideation event had a current diagnosis of ODD, but other relevant medical diagnoses or history of suicidal behavior or ideation was not noted.

Of the nine suicidal behavior or ideation events in the atomoxetine group, six occurred in patients from the United States (6/1389; $0.43 \%$ ) and three were in patients from outside the United States (3/ $1056 ; 0.28 \%)$. When stratified by region, differences were not significant overall or by individual region $(p \geq 0.23)$.

\section{Suicide-related events. Text-string search: Adult placebo-controlled trials}

In this data set, no completed suicides or suicidal behavior events were identified in either treatment arm. The frequency of suicidal ideation events in adult patients was similar between the atomoxetine $(n=2 ; 0.11 \%)$ and placebo $(n=2 ; 0.12 \%)$ groups, and the risk for suicidal ideation was not different between groups $(\mathrm{MHRR}=0.96 ; 95 \%$ CI 0.19, 4.74; $p=0.96)$ (Table 3). One atomoxetine-treated patient with a suicidal ideation event had comorbid conditions of anxiety and depression at baseline. The remaining three patients with a suicidal ideation event did not re- port any history of suicidal behavior or ideation or any relevant historical diagnosis or comorbid conditions. All events of suicidal ideation occurred in patients from the United States. Possible suicidal behavior or ideation events were also similar between the atomoxetine and placebo groups.

\section{C-SSRS rated suicide-related events from available pediatric and adult placebo-controlled trials}

In pediatric Study LYEB, no ratings for suicidal behavior were reported for either treatment group, which was consistent with the text-string search for this trial. Suicidal ideation C-SSRS ratings occurred in the atomoxetine $(5 / 115 ; 4.3 \%)$ and placebo $(2 / 86$; $2.3 \%)$ groups, but the difference was not statistically significant $(p=0.70)$. In the text-string search for this study only, no suicidal ideation events were identified from either the atomoxetine or placebo groups.

In adult Studies LYDZ and LYEE collectively, C-SSRS ratings for suicidal behavior (preparatory, aborted, interrupted, or nonfatal attempt) occurred for 1/407 patients in the atomoxetine group and $3 / 417$ patients in the placebo group. No suicidal behavior rating in either of these two studies for either atomoxetine or placebo was identified from the text-string search. C-SSRS ratings for suicidal ideation occurred in 4/407 patients in the atomoxetine group and $6 / 417$ patients in the placebo group. No suicidal ideation event for either the atomoxetine or placebo group was identified from these two studies using the text-string search.

\section{Discussion}

In this analysis of double-blind, placebo-controlled, atomoxetine clinical trials, the overall incidence of suicidal behavior or ideation in atomoxetine-treated pediatric patients with ADHD was uncommon. The incidence of combined suicidal behavior or ideation events in atomoxetine-treated pediatric patients was $0.37 \%$, in

Table 3. Suicidal Behavior and/or Ideation in Atomoxetine Adult ADHD Trials: Text-String Search

\begin{tabular}{|c|c|c|c|c|c|c|c|}
\hline Outcome & $\mathrm{n}$ & $\operatorname{ATX} \mathrm{n}(\%)$ & $\mathrm{n}$ & $P B O \mathrm{n}(\%)$ & Risk ratio $^{\mathrm{a}}$ & $\mathrm{p}$ value & $\begin{array}{c}\text { Risk ratio } \\
95 \% \text { CI }\end{array}$ \\
\hline \multicolumn{8}{|l|}{ All studies (all regions) } \\
\hline $\begin{array}{l}\text { Suicide completed/attempt/behavior } \\
\text { (FDA Codes } 1,2,3)\end{array}$ & 1764 & $0(0)$ & 1601 & $0(0)$ & N/A & N/A & N/A \\
\hline $\begin{array}{l}\text { Suicide completed/attempt/behavior/ideation } \\
\quad \text { (FDA Codes } 1,2,3,4)\end{array}$ & 1764 & $2(0.11)$ & 1601 & $2(0.12)$ & 0.96 & 0.96 & $0.19,4.74$ \\
\hline Suicidal ideation only (FDA Code 4) & 1764 & $2(0.11)$ & 1601 & $2(0.12)$ & 0.96 & 0.96 & $0.19,4.74$ \\
\hline \multicolumn{8}{|l|}{ Possible suicidal behavior or ideation } \\
\hline FDA Codes $1,2,3,4,5,6$ & 1764 & $3(0.17)$ & 1601 & $5(0.31)$ & 0.67 & 0.55 & $0.18,2.49$ \\
\hline \multirow[t]{2}{*}{ FDA Codes $1,2,3,4,5,6$, and 9} & 1764 & $5(0.28)$ & 1601 & $7(0.44)$ & 0.77 & 0.65 & $0.25,2.41$ \\
\hline & $\mathrm{n}$ & $\operatorname{ATX} \mathrm{n}(\%)$ & $\mathrm{n}$ & $P B O \mathrm{n}(\%)$ & $\begin{array}{c}\text { Overall } \\
\text { risk ratio }^{\mathrm{a}}\end{array}$ & $\begin{array}{l}\text { Overall } \\
\mathrm{p} \text { value }\end{array}$ & $\begin{array}{c}\text { Risk ratio } \\
95 \% \text { CI }\end{array}$ \\
\hline \multicolumn{8}{|l|}{ By region (all studies) } \\
\hline $\begin{array}{l}\text { Suicide completed/attempt/behavior/ideation } \\
\text { (FDA Codes } 1,2,3,4)\end{array}$ & 1764 & $2(0.11)$ & 1601 & $2(0.12)$ & 0.95 & 0.95 & $0.19,4.71$ \\
\hline Australia, Canada, Europe & 19 & $0(0)$ & 20 & $0(0)$ & N/A & N/A & N/A \\
\hline Japan & 124 & $0(0)$ & 125 & $0(0)$ & N/A & N/A & N/A \\
\hline United States & 1537 & $2(0.13)$ & 1371 & $2(0.15)$ & 0.95 & 0.95 & $0.19,4.71$ \\
\hline Other & 84 & $0(0)$ & 85 & $0(0)$ & N/A & N/A & N/A \\
\hline
\end{tabular}

${ }^{\mathrm{a}}$ Mantel-Haenszel relative risk analysis.

ADHD, attention-deficit/hyperactivity disorder; ATX, atomoxetine; CI, confidence interval; FDA, United States Food and Drug Administration; PBO, placebo. 
which all but one of the nine events was categorized as suicidal ideation. Although not statistically significantly different, suicidal ideation was reported more frequently in atomoxetine-treated pediatric patients, mostly $<12$ years of age, compared with those taking placebo. The overall risk of suicidal behavior and/or ideation events in the current meta-analysis $(\mathrm{MHRR}=1.57$; 95\% CI 0.53 , $4.71 ; p=0.42$ ), which included a larger patient pool, was consistent with, if not lower than, the previous meta-analysis of atomoxetine trials $(\mathrm{MHRR}=2.49 ; 95 \% \mathrm{CI} 0.64,9.78 ; p=0.19)$. The one report of suicidal behavior (possible suicide attempt) in the atomoxetinetreated pediatric population had been previously identified in the original meta-analysis and, therefore, in the current analysis, the risk for suicidal behavior did not increase $(\mathrm{MHRR}=1.19 ; 95 \% \mathrm{CI}$ 0.05, 28.96; $p=0.91$ ) (Bangs et al. 2008b).

Results from the current analysis of risk for suicidal behavior or ideation in atomoxetine-treated pediatric patients are consistent with published reports. In a separate Lilly-sponsored analysis of randomized, double-blind, controlled atomoxetine and methylphenidate pediatric ADHD trials, suicidal behavior and/or ideation categorized by FDA codes occurred in $1 / 559(0.18 \%)$ in the atomoxetine group compared with $1 / 465(0.22 \%)$ in the methylphenidate group. The risk was not significantly different between groups (MHRR $=0.52 ; 95 \%$ CI 0.06, 4.54; $p=0.56$ ) (Bushe and Savill 2013). In an analysis of 714 pediatric patients who took atomoxetine for at least 3-4 years in a long-term open-label study, 2 suicide attempts $(0.3 \%), 11$ cases of suicidal ideation $(1.5 \%)$, and 1 case of suicidal behavior $(0.1 \%)$ were reported (Donnelly et al. 2009). In a United Kingdom study, no cases of suicide were identified with atomoxetine from a pool of $>5000$ patients ages 2-21 years who were prescribed stimulants or atomoxetine between 1993 and 2006 (McCarthy et al. 2009). An observational cohort postmarketing surveillance United Kingdom study of 2544 patients (median age 12 years) treated with atomoxetine, reported 23 patients with suicidal ideation. Nine of the 23 cases reported a suicide attempt during treatment, of which 8 were atomoxetine overdose (Davies et al. 2009). Overall, reports of suicide-related behavior were infrequent, which is consistent with the results of the present study.

Suicide-related behavior or ideation was reported in this study with relatively low frequency. Suicidal behaviors are not uncommon in the pediatric population globally, and particularly in those with mental illness, including ADHD (Manor et al. 2010; Impey and Heun 2012; Perou et al. 2013). In the United States alone in 2010, suicide was the second leading cause of death among adolescents 12-17 years of age (Perou et al. 2013) These suicide-related behaviors have long been associated to the idea that younger adolescents have immature cognitive and emotional abilities to cope with problems. The intensity of being overwhelmed increases the risk for suicidal ideation. In moving through the adolescent stages, thoughts of suicide may become more common (Vander Stoep et al. 2009). The challenge of coping may be greater in adolescents with ADHD. The rate of patients with ADHD who exhibit suicide-related behaviors has been reported to be nearly double the rate of the control population (Impey and Heun 2012). In the current study, nearly all cases of suicidal ideation occurred in patients $<12$ years of age. It has been reported that early adolescent patients (11-14 years old) with ADHD appear to be at greater risk for completion of suicide than later adolescent patients (15-21 years old). Although comorbid mood disorders have been associated with increased risk of suicide-related behaviors, impulsivity may be an independent factor leading to increased risk, particularly in patients with ADHD, noting that impulsivity symptoms may also be present in the inattentive subtype (Greening et al. 2008; Manor et al. 2010; Impey and Heun 2012). Although the risk for suicidal behavior and/or ideation in pediatric patients treated with atomoxetine was low, close monitoring for changes in behavior in this pediatric ADHD population is particularly critical. Families and caregivers of pediatric patients with ADHD being treated with ADHD pharmacotherapy, including atomoxetine, should be alerted about the need to monitor patients for the emergence of agitation, irritability, unusual changes in behavior, and other symptoms, including emergence of suicidality (Graham et al. 2011).

In this expanded analysis of the database of double-blind, placebo-controlled adult atomoxetine clinical trials, there was no evidence of increased risk for completed suicide or suicidal behavior. The risk for suicidal ideation in atomoxetine-treated adults was minimal $(0.11 \%)$ and comparable with that for placebo-treated patients $(0.12 \%)$.

C-SSRS results were limited to three atomoxetine clinical trials. In these studies, the C-SSRS detected suicidal ideation, whereas no signals were detected with the text-string method. These results are too premature to generalize to the overall population in this metaanalysis. The patient populations in each study utilizing C-SSRS were unique, and specific to either a comorbid dyslexia diagnosis, a region of study, or a young adult population.

Retrospective analysis has limitations, and results should be viewed with that consideration. The population evaluated may be an inherent limitation, as suicidal behavior or ideation may be lower in a clinical trial population given that patients with a history of suicidal behavior are generally excluded. Further, routine office visits and more frequent monitoring by clinicians may provide nonpharmacotherapeutic value and result in reduced ideation. Conversely, a clinical trial setting and routine monitoring may encourage patients to be more forthcoming and, therefore, result in increased reporting of suicide-related thoughts or behaviors. Another limiting factor is the lack of a non-ADHD control population; however, a placebo-controlled population strengthened these comparisons. Another limitation to the analysis is that clinical trial duration in this data set was limited to a few months. Longer time in treatment may have resulted in the emergence of more reports of suicidal ideation. The greatest strength of this study is evaluation of an expanded pool of patients, which supports the findings from the original analysis of risk.

\section{Conclusions}

In this data set, reports of suicidal behavior or ideation were uncommon in children, adolescents, and adults treated with atomoxetine, and no completed suicides were reported. Although the evidence suggests minimal risk with atomoxetine treatment, patients with ADHD and pediatric patients in particular should be monitored appropriately during treatment. Close observation for clinical worsening, suicide-related behavior or ideation, and unusual changes in behavior, especially during the initial few months of a course of drug therapy or at times of dose changes, either increases or decreases, is advised. In the adult ADHD population treated with atomoxetine, there was no evidence of greater risk over placebo for either suicidal behavior or ideation. Overall, the risks and benefits must be factored when considering pharmacotherapy treatment for ADHD.

\section{Clinical Significance}

The frequency of suicidal behavior or ideation is often greater in children, adolescents, and adults with psychiatric disorders, including ADHD, than in those without mental illness. In 2005, Lilly 
conducted a meta-analysis of pediatric placebo- or active-controlled atomoxetine trials and evaluated RRs for suicidal behavior or ideation from the adverse events database using text-string search. The findings from the meta-analysis revealed that relative to placebo, the RR for suicidal behavior in pediatric patients treated with atomoxetine was 1.19 . The current meta-analysis expanded the evaluation from a much larger pool of pediatric patients in addition to adult patients from the double-blind, placebo-controlled atomoxetine clinical trial database to continue surveillance for the risk of suicidal behavior or ideation. The information will provide clinicians safety information to consider prior to the initiation of or during pharmacotherapy treatment of ADHD, particularly in the pediatric population.

\section{Acknowledgments}

The authors would like to thank Millie S. Hollandbeck for assistance with the preparation of this manuscript and Cara Campora for editing assistance.

\section{Disclosures}

All authors are employees and minor shareholders of Eli Lilly and Company and/or one of its subsidiaries.

\section{References}

Adler LA, Liebowitz M, Kronenberger W, Qiao M, Rubin R, Hollandbeck M, Deldar A, Schuh K, Durell T: Atomoxetine treatment in adults with attention-deficit/hyperactivity disorder and comorbid social anxiety disorder. Depress Anxiety 26:212-221, 2009a.

Adler LA, Spencer T, Brown TE, Holdnack J, Saylor K, Schuh K, Trzepacz PT, Williams DW, Kelsey D: Once-daily atomoxetine for adult attention-deficit/hyperactivity disorder: a 6-month, doubleblind trial. J Clin Psychopharmacol 29:44-50, 2009 b.

Adler, LA, Spencer TJ, Levine LR, Ramsey JL, Tamura R, Kelsey D, Ball SG, Allen AJ, Biederman J: Functional outcomes in the treatment of adults with ADHD. J Atten Disord 11:720-727, 2008.

Allen AJ, Kurlan RM, Gilbert DL, Coffey BJ, Linder SL, Lewis DW, Winner PK, Dunn DW, Dure LS, Sallee FR, Milton DR, Mintz MI, Ricardi RK, Erenberg G, Layton LL, Feldman PD, Kelsey DK, Spencer TJ: Atomoxetine treatment in children and adolescents with ADHD and comorbid tic disorders. Neurology 65:1941-1949, 2005.

American Psychiatric Association: Diagnostic and Statistical Manual of Mental Disorders, 4th ed., Text Revision. Washington, DC: American Psychiatric Association; 2000.

Bangs ME, Emslie GJ, Spencer TJ, Ramsey JL, Carlson C, Bartky EJ, Busner J, Duesenberg DA, Harshawat P, Kaplan SL, Quintana H, Allen AJ, Sumner CR, Atomoxetine ADHD and Comorbid MDD Study Group: Efficacy and safety of atomoxetine treatment in adolescents with attention-deficit/hyperactivity disorder and major depression. J Child Adolesc Psychopharmacol 17:407-420, 2007.

Bangs ME, Hazell P, Danckaerts M, Hoare P, Coghill DR, Wehmeier PM, Williams DW, Moore RJ, Levine L, Atomoxetine ADHD/ ODD Study Group: Atomoxetine for the treatment of attentiondeficit/hyperactivity disorder and oppositional defiant disorder. Pediatrics 121:e314-320, 2008a.

Bangs ME, Tauscher-Wisniewski S, Polzer J, Zhang S, Acharya N, Desaiah D, Allen AJ: Meta-analysis of suicide-related events in atomoxetine-treated patients. Presented as a poster at the 52nd Annual Meeting of the American Academy of Child and Adolescent Psychiatry, Toronto, Ontario, Canada, October 18-23, 2005.

Bangs ME, Tauscher-Wisniewski S, Polzer J, Zhang S, Acharya N, Desaiah D, Trzepacz PT, Allen AJ: Meta-analysis of suicide-related behavior events in patients treated with atomoxetine. J Am Acad Child Adolesc Psychiatry 47:209-218, 2008b.

Barkley RA, Murphy KR, Fischer M: ADHD in Adults: What the Science Says. New York: The Guilford Press; 2008.

Biederman J: Attention-deficit/hyperactivity disorder: a selective overview. Biol Psychiatry 57:1215-1220, 2005.

Biederman J, Faraone SV: Current concepts on the neurobiology of attention-deficit/hyperactivity disorder. J Atten Disord 6 Suppl 1:S7-S16, 2002.

Block SL, Kelsey D, Coury D, Lewis D, Quintana H, Sutton V, Schuh $\mathrm{K}$, Allen AJ, Sumner C: Once-daily atomoxetine for treating pediatric attention-deficit/hyperactivity disorder: comparison of morning and evening dosing. Clin Pediatr (Phila) 48:723-733, 2009.

Brent D, Perper JA, Goldstein CE, Kolko DJ, Allan MJ, Allman CJ, Zelenak JP: Risk factors for adolescent suicide. A comparison of adolescent suicide victims with suicidal inpatients. Arch Gen Psychiatry 45:581-588, 1988.

Bushe CJ, Savill NC: Suicide related events and attention deficit hyperactivity disorder treatments in children and adolescents: a meta-analysis of atomoxetine and methylphenidate comparator clinical trials. Child Adolesc Psychiatry Ment Health 7:19, 2013.

Bymaster FP, Katner J, Nelson DL, Hemrick-Luecke SK, Threlkeld PG, Heiligenstein JH, Morin SM, Gehlert DR, Perry KW: Atomoxetine increases extracellular levels of norepinephrine and dopamine in prefrontal cortex of rat: a potential mechanism for efficacy in attention deficit/hyperactivity disorder. Neuropsychopharmacology 27:699-711, 2002.

Centers for Disease Control and Prevention: Attention Deficit Hyperactivity Disorder Among Children Aged 5-17 Years in the United States, 1998-2009. Available at http://www.cdc.gov/nchs/ data/databriefs/db70.pdf Accessed June 28, 2013.

Davies M, Cornelius V, Fogg C, Wilton L, Shakir S: Characteristics of patients prescribed atomoxetine in England: Data from a first interim modified prescription event monitoring study. Drug Saf 32: 976, 2009.

de Jong CGW, Van De Voorde S, Roeyers H, Raymaekers R, Allen AJ, Knijff S, Verhelst H, Temmink AH, Smit LM, RodriquesPereira R, Vandenberghe D, van Welsen I, ter Schuren L, Al-Hakim M, Amin A, Vlasveld L, Oosterlaan J, Sergeant JA: Differential effects of atomoxetine on executive functioning and lexical decision in attention-deficit/hyperactivity disorder and reading disorder. J Child Adolesc Psychopharmacol 19:699-707, 2009.

Dell'agnello G, Maschietto D, Bravaccio C, Calamoneri F, Masi G, Curatolo P, Besana D, Mancini F, Rossi A, Poole L, Escobar R, Zuddas A, LYCY Study Group: Atomoxetine hydrochloride in the treatment of children and adolescents with attention-deficit/hyperactivity disorder and comorbid oppositional defiant disorder: A placebo-controlled Italian study. Eur Neuropsychopharmacol 19:822-834, 2009.

Dittmann RW, Schacht A, Helsberg K, Schneider-Fresenius C, Lehmann M, Lehmkuhl G, Wehmeier PM: Atomoxetine versus placebo in children and adolescents with attention-deficit/hyperactivity disorder and comorbid oppositional defiant disorder: A doubleblind, randomized, multicenter trial in Germany. J Child Adolesc Psychopharmacol 21:1-14, 2011.

Donnelly C, Bangs M, Trzepacz P, Jin L, Zhang S, Witte MM, Ball SG, Spencer TJ: Safety and tolerability of atomoxetine over 3 to 4 years in children and adolescents with ADHD. J Am Acad Child Adolesc Psychiatry 48:176-185, 2009.

Durell TM, Adler LA, Williams DW, Deldar A, McGough JJ, Glaser PE, Rubin RL, Pigott TA, Sarkis EH, Fox BK: Atomoxetine treatment of attention-deficit/hyperactivity disorder in young adults with assessment of functional outcomes: a randomized, doubleblind, placebo-controlled clinical trial. J Clin Psychopharmacol 33:45-54, 2013. 
Gau SSF, Huang Y-S, Soong W-T, Chou MC, Chou WJ, Shang CY, Tseng WL, Allen AJ, Lee P: A randomized, double-blind, placebocontrolled clinical trial on once-daily atomoxetine hydrochloride in Taiwanese children and adolescents with attention-deficit/hyperactivity disorder. J Child Adolesc Psychopharmacol 17:447-459, 2007.

Geller D, Donnelly C, Lopez F, Rubin R, Newcorn J, Sutton V, Bakken R, Paczkowski M, Kelsey D, Sumner C: Atomoxetine treatment for pediatric patients with attention-deficit/hyperactivity disorder with comorbid anxiety disorder. J Am Acad Child Adolesc Psychiatry 46:1119-1127, 2007.

Graham J, Banaschewski T, Buitelaar J, Coghill D, Danckaerts M, Dittmann RW, Döpfner M, Hamilton R, Hollis C, Holtmann M, Hulpke-Wette M, Lecendreux M, Rosenthal E, Rothenberger A, Santosh P, Sergeant J, Simonoff E, Sonuga-Barke E, Wong IC, Zuddas A, Steinhausen HC, Taylor E, European Guidelines Group: European guidelines on managing adverse effects of medication for ADHD. Eur Child Adolesc Psychiatry 20:17-37, 2011.

Greening L, Stoppelbein L, Fite P, Dhossche D, Erath S, Brown J, Cramer R, Young L: Pathways to suicidal behaviors in childhood. Suicide Life Threat Behav 38:35-45, 2008.

Greenland S, Robins JM: Estimation of a common effect parameter from sparse follow-up data. Biometrics 41:55-68, 1985.

Harfterkamp M, van de Loo-Neus G, Minderaa RB, van der Gaag RJ, Escobar R, Schacht A, Pamulapati S, Buitelaar JK, Hoekstra PJ: A randomized double-blind study of atomoxetine versus placebo for attention-deficit/hyperactivity disorder symptoms in children with autism spectrum disorder. J Am Acad Child Adolesc Psychiatry 51:733-741, 2012.

Hirata Y, Goto T, Takita Y, Trzepacz PT, Allen AJ, Song DH, Gau S, Ichikawa H, Takahashi M: Efficacy and safety of atomoxetine in Asian adults with ADHD: A multinational, 10-week, randomized, double-blind, placebo-controlled Asian study. Presented as a poster at the 28th CINP Congress of Neuropsychopharmacology Meeting, Stockholm, Sweden, June 3-7, 2012.

Houston K, Hawton K, Shepperd R: Suicide in young people aged 15-24: A psychological autopsy study. J Affect Disord 63:159-170, 2001.

Impey M, Heun R: Completed suicide, ideation and attempt in attention deficit hyperactivity disorder. Acta Psychiatr Scand 125:93102, 2012.

James A, Lai FH, Dahl C: Attention deficit hyperactivity disorder and suicide: A review of possible associations. Acta Psychiatr Scand 110:408-415, 2004.

Kelsey DK, Sumner CR, Casat CD, Coury DL, Quintana H, Saylor KE, Sutton VK, Gonzales J, Malcolm SK, Schuh KJ, Allen AJ: Once-daily atomoxetine treatment for children with attention-deficit/ hyperactivity disorder, including an assessment of evening and morning behavior: A double-blind, placebo-controlled trial. Pediatrics 114:e1-e8, 2004.

Kessler RC, Adler L, Barkley R, Biederman J, Conners CK, Demler O, Faraone SV, Greenhill LL, Howes MJ, Secnik K, Spencer T, Ustun TB, Walters EE, Zaslavsky AM: The prevalence and correlates of adult ADHD in the United States: Results from the National Comorbidity Survey Replication. Am J Psychiatry 163: 716-723, 2006.

Manor I, Gutnik I, Ben-Dor DH, Apter A, Sever J, Tyano S, Weizman A, Zalsman G: Possible association between attention deficit hyperactivity disorder and attempted suicide in adolescents - a pilot study. Eur Psychiatry 25:146-150, 2010.

Martenyi F, Zavadenko NN, Jarkova NB, Yarosh AA, Soldatenkova VO, Bardenstein LM, Kozlova IA, Neznanov NG, Maslova OI, Petrukhin AS, Sukchotina NK, Zykov VP: Atomoxetine in children and adolescents with attention-deficit/hyperactivity disorder: A 6week, randomized, placebo-controlled, double-blind trial in Russia. Eur Child Adolesc Psychiatry 19:57-66, 2010.
McCarthy S, Cranswick N, Potts L, Taylor E, Wong IC: Mortality associated with attention-deficit hyperactivity disorder (ADHD) drug treatment: A retrospective cohort study of children, adolescents, and young adults using the General Practice Research Database. Drug Saf 32:1089-1096, 2009.

Michelson D, Adler L, Spencer T, Reimherr FW, West SA, Allen AJ, Kelsey D, Wernicke J, Dietrich A, Milton D: Atomoxetine in adults with ADHD: Two randomized, placebo-controlled studies. Biol Psychiatry 53:112-120, 2003.

Michelson D, Allen AJ, Busner J, Casat C, Dunn D, Kratochvil C, Newcorn J, Sallee FR, Sangal RB, Saylor K, West S, Kelsey D, Wernicke J, Trapp NJ, Harder D: Once-daily atomoxetine treatment for children and adolescents with attention-deficit/hyperactivity disorder: A randomized, placebo-controlled study. Am J Psychiatry 159:1896-1901, 2002.

Michelson D, Faries D, Wernicke J, Kelsey D, Kendrick K, Sallee FR, Spencer T, Atomoxetine ADHD Study Group: Atomoxetine in the treatment of children and adolescents with attention-deficit/hyperactivity disorder: A randomized, placebo-controlled, dose-response study. Pediatrics 108:e83, 2001.

Montoya A, Hervas A, Cardo E, Artigas J, Mardomingo MJ, Alda JA, Gastaminza X, García-Polavieja MJ, Gilaberte I, Escobar R: Evaluation of atomoxetine for first-line treatment of newly diagnosed, treatment-naïve children and adolescents with attention deficit/ hyperactivity disorder. Curr Med Res Opin 25:2745-2754, 2009.

Newcorn JH, Kratochvil CJ, Allen AJ, Casat CD, Ruff DD, Moore RJ, Michelson D: Atomoxetine and osmotically released methylphenidate for the treatment of attention deficit hyperactivity disorder: Acute comparison and differential response. Am J Psychiatry 165: 721-730, 2008.

O’Donnell L, Stueve A, Wilson-Simmons R: Aggressive behaviors in early adolescence and subsequent suicidality among urban youths. J Adolesc Health 37:517.e15-517.e25, 2005.

Perou R, Bitsko RH, Blumberg SJ, Pastor P, Ghandour RM, Gfroerer JC, Hedden SL, Crosby AE, Visser SN, Schieve LA, Parks SE, Hall JE, Brody D, Simile CM, Thompson WW, Baio J, Avenevoli S, Kogan MD, Huang LN; Centers for Disease Control and Prevention: Mental health surveillance among children-United States, 2005-2011. MMWR Surveill Summ 62 Suppl 2:1-35, 2013.

Posner K, Brown GK, Stanley B, Brent DA, Yershova KV, Oquendo MA, Currier GW, Melvin GA, Greenhill L, Shen S, Mann JJ: The Columbia-Suicide Severity Rating Scale: Initial validity and internal consistency findings from three multisite studies with adolescents and adults. Am J Psychiatry 168:1266-1277, 2011.

Posner K, Oquendo MA, Gould Madelyn, Stanley B, Davies M: Columbia Classification Algorithm of Suicide Assessment (C-CASA): Classification of suicidal events in the FDA's pediatric suicidal risk analysis of antidepressants. Am J Psychiatry 164:1035-1043, 2007.

Sato T: On the variance estimator for the Mantel-Haenszel risk difference. Biometrics 45:1323-1324, 1989.

Shafii M, Steltz-Lenarsky J, Derrick AM, Beckner C, Whittinghill JR: Comorbidity of mental disorders in the post-mortem diagnosis of completed suicide in children and adolescents. J Affect Disord 15:227-233, 1988.

Simon V, Czobor P, Bálint S, Mészáros A, Bitter I: Prevalence and correlates of adult attention-deficit hyperactivity disorder: metaanalysis. Br J Psychiatry 194:204-211, 2009.

Spencer T, Biederman J, Wilens T: Attention-deficit/hyperactivity disorder and comorbidity. Pediatr Clin North Am 46:915-927, 1999.

Spencer TJ, Heiligenstein JH, Biederman J, Faries DE, Kratochvil CJ, Conners CK, Potter WZ: Results from 2 proof of concept, placebocontrolled studies of atomoxetine in children with attention-deficit/ hyperactivity disorder. J Clin Psychiatry 63:1140-1147, 2002. 
Svanborg P, Thernlund G, Gustafsson PA, Hagglof B, Poole L, Kadesjo B: Efficacy and safety of atomoxetine as add-on to psychoeducation in the treatment of attention deficit/hyperactivity disorder: A randomized, double-blind, placebo-controlled study in stimulant-naïve Swedish children and adolescents. Eur Child Adolesc Psychiatry 18:240-249, 2009.

Swanson CJ, Perry KW, Koch-Krueger S, Katner J, Svensson KA, Bymaster FP: Effect of the attention deficit/hyperactivity disorder drug atomoxetine on extracellular concentrations of norepinephrine and dopamine in several brain regions of the rat. Neuropharmacology 50:755-760, 2006.

Takahashi M, Takita Y, Yamazaki K, Hayashi T, Ichikawa H, Kambayashi Y, Koeda T, Oki J, Saito K, Takeshita K, Allen AJ: A randomized, double-blind, placebo-controlled study of atomoxetine in Japanese children and adolescents with attention-deficit/hyperactivity disorder. J Child Adolesc Psychopharmacol 19:341-350, 2009.

United States Department of Health and Human Services Food and Drug Administration Center for Drug Evaluation and Research: Guidance for Industry Suicidality: Prospective Assessment of Occurrence in Clinical Trials. Available at http://www.fda.gov/ downloads/Drugs/GuidanceComplianceRegulatoryInformation/ Guidances/UCM225130.pdf Accessed June 28, 2013.

Vander Stoep A, McCauley E, Flynn C, Stone A: Thoughts of death and suicide in early adolescence. Suicide Life Threat Behav 39:599, 2009.

Wehmeier PM, Schacht A, Ulberstad F, Lehmann M, Schneider-Fresenius C, Lehmkuhl G, Dittmann RW, Banaschewski T: Does atomoxetine improve executive function, inhibitory control, and hyperactivity? Results from a placebo-controlled trial using quantitative measurement technology. J Clin Psychopharmacol 32:653-660, 2012.

Weiss M, Tannock R, Kratochvil C, Dunn D, Velez-Borras J, Thomason C, Tamura R, Kelsey D, Stevens L, Allen AJ: A randomized, placebo-controlled study of once-daily atomoxetine in the school setting in children with ADHD. J Am Acad Child Adolesc Psychiatry 44:647-655, 2005.
Wietecha L, Williams D, Shaywitz S, Shaywitz B, Hooper SR, Wigal $\mathrm{SB}$, Dunn D, McBurnett K: Atomoxetine improved attention in children and adolescents with attention-deficit/hyperactivity disorder and dyslexia in a 16 week, acute, randomized, double-blind trial. J Child Adolesc Psychopharmacol 23:605-613, 2013.

Wilens TE, Adler LA, Weiss MD, Michelson D, Ramsey JL, Moore RJ, Renard D, Brady KT, Trzepacz PT, Schuh LM, Ahrbecker LM, Levine LR; Atomoxetine ADHD/SUD Study Group: Atomoxetine treatment of adults with ADHD and comorbid alcohol use disorders. Drug Alcohol Depend 96:145-154, 2008.

Willcutt EG: The prevalence of DSM-IV attention-deficit/hyperactivity disorder: A meta-analytic review. Neurotherapeutics 9: 490-499, 2012.

Willcutt EG, Pennington BF, Chhabildas NA, Friedman MC, Alexander J: Psychiatric comorbidity associated with DSM-IV ADHD in a nonreferred sample of twins. J Am Acad Child Adolesc Psychiatry 38:1355-1362, 1999.

Wittchen HU, Jacobi F, Rehm J, Gustavsson A, Svensson M, Jönsson B, Olesen J, Allgulander C, Alonso J, Faravelli C, Fratiglioni L, Jennum P, Lieb R, Maercker A, van Os J, Preisig M, SalvadorCarulla L, Simon R, Steinhausen HC: The size and burden of mental disorders and other disorders of the brain in Europe 2010. Eur Neuropsychopharmacol 21:655-679, 2011.

Young JL, Sarkis E, Qiao M, Wietecha L: Once-daily treatment with atomoxetine in adults with attention-deficit/hyperactivity disorder: A 24-week, randomized, double-blind, placebo-controlled trial. Clin Neuropharmacol 34:51-60, 2011.

Address correspondence to: Mark E. Bangs, MD Eli Lilly and Company Lilly Corporate Center Indianapolis, IN 46285

E-mail: bangsme@lilly.com 